\title{
Institutional Animal Care and Use Committees and the Moderate Position
}

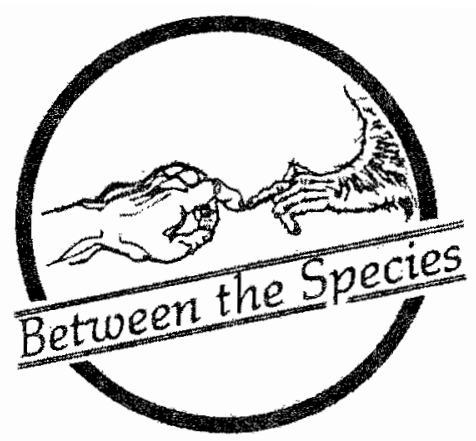

\author{
Wendell Stephenson \\ Lewis and Clark College
}

\begin{abstract}
Editors' Note: This essay by Professor Stephenson and the response to it by Professor Gendin were presented at the Eastern Division meetings of the Society for the Study of Ethics and Animals held in Atlanta, Georgia, December, 1989.
\end{abstract}

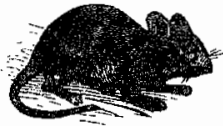

In his article on IACUCs, ${ }^{1} \mathrm{~L}$. Finsen provides three useful categories of ethical perspectives one can take on research using nonhuman animals. One can hold to a laissez-faire approach, a 'moderate' approach, or an abolitionist approach. The first considers that all research on nonhuman animals is justifiable provided it adheres to 'humane' standards of minimizing pain and distress; the third considers that no research on nonhuman animals is justifiable whether it is 'humanely' conducted or not; and the second, 'moderate', approach, holds that some research is justifiable, some not, depending on the purpose of the research, and that all justifiable reseanch must adhere to 'humane' standards.

In this paper I want to 1) relate how a 'moderate' was appointed to the Institutional Animal Care and Use Committee (AACUC) at the Oregon Regional Primate Research Center (ORPRC) and some of the results of this; 2) raise questions as to the proper place for the sort of ethical concern for animals that Finsen supports; 3) indicate why I'm a 'moderate'.

1. I was appointed as the lay, outside, member of the IACUC at ORPRC by the Director of ORPRC after an interview with him and the director of public relations. In this interview, the Director asked me whether I had 'an open mind' about research using animals. I said I did, and shortly was asked to become a member of the committee. I was not asked whether I was for this, that, or the other type of research nor whether I was against this, that, or the other. And the Director seemed well aware that I might vote against various research proposals and that I might ask various awkward or unwelcome questions. He did not appear to want a layperson who would simply rubber stamp whatever proposal met the approval of the other members of the committee, and there was some indication that he was even desirous of having a person on the committee who would raise important questions that would not otherwise be raised. I believe that, by the letter of the law, he did not have to have these concerns, and that he could have attempted to appoint a rubber stamp, but I think there are powerful political reasons, constituted primarily by the animal rights movement, favoring the course of action this Director took, and that these reasons apply to many other directors of such institutions as the ORPRC across the US.

After being appointed, I was given the $\mathrm{NIH}$ guide for the care and use of laboratory animals. This is the Bible for IACUCs. It would not be unfair to say that this guide is most consonant with a laissez-faire

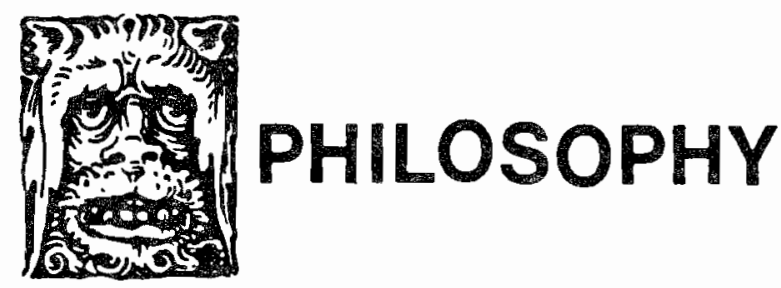


approach to research using animals but that it is not inconsistent with a 'moderate' approach. Specifically, it does not disallow the question, Does the purpose of this research and the likely benefits either to humans or to animals warrant using animals in the way proposed? That it does not entail or mandate this question seems to me to be a defect in it, but that, except on very strict and determined constructions of it, it doesn't disallow the asking of this question means that it makes room for 'moderates' on IACUCs.

The IACUC on which I serve requires that each researcher submit to the committee a 'Notice of Intent' (NOI). Shortly after I joined the committee this NOI was revised. The chair solicited help from members, and $I$ requested that there be a section in which the researcher is required to answer the following directive: 'State, in lay terms, how your proposed research is likely to benefit human or animal health or well-being'. This request was adopted. This means that each researcher has to say something in this section, and that something is, for me (and I think for any 'moderate'), of fundamental importance for evaluating the justifiability of the proposed project.

I now give an example of a controversy generated by thinking about this question, which is also an example of the impact a 'moderate' can have on an IACUC. At ORPRC, a good deal of research pertains to the problem of human infertility (HIR=Human Infertility Research). Some of this research involves the use of monkeys and baboons. This 'use' involves killing some of them, separating infants from their mothers at birth, as well as subjecting them to various operations and manipulations (not to mention the original acts of capturing them or their progenitors and caging them in individual cages). The justification for all this is 'the problem of human infertility.' In essence, this problem is that some couples who want to have children in the nomal biological way (the figure may be as high as $20 \%$ of all such couples who want to have children in the normal way) cannot do so without medical help. So, in short, the problem is that some couples cannot fulfill their desire to have children. Is the possibility of alleviating this a sufficient justification for 'using' monkeys and baboons in the ways indicated above? I asked this question of the committee and began arguing that it was not. The essence of my argument is that nonhuman primates should be subjected to the types of uses above indicated only if: 1) seriously lifethreatening diseases or disabilities or seriously life- diminishing diseases or disabilities are in question; 2) there is good reason to believe that they are likely to be ameliorated by using animals; 3 ) it is not now plausible to argue that humans are themselves responsible for the diseases and disabilities from which they suffer due to activities they could abstain from if they would. I was able to do this because of the question on the NOI pertaining to the likely benefits to hurnans or animals. My questioning generated much heat and activity and some rethinking and reevaluation, and still continues to do so, though my arguments have not, by any means, produced the changes I think desirable and even obligatory. (Perhaps they shouldn't; perhaps they're not convincing. The point is, there was and is a forum for their getting stated and the potential for their having the desired effect.)

2. As Finsen brings out in his article, the authorized function of the IACUCs is to see to it that the NIH guidelines are followed. These guidelines, as Finsen also brings out, lean toward the laissez-faire perspective and do not require "discussion and evaluation of the ethical dimensions of proposed and ongoing research involving animals," if "ethical dimensions" is here taken to encompass questions outside those of pain, suffering, the performance of multiple major surgeries on one animal, and the method of killing the animal. Now, in my view, the NIH guidelines should require a broader discussion than they do. But I think it is insufficiently recognized that Congress has authorized and provided the funds for institutions such as ORPRC to do basic research using a variety of nonhuman animals, thereby indicating approval of such research. It is not at all clear that, given this approval, it is required that it direct the NIH to pass regulations which require that researchers have their proposals subjected to wideranging ethical scrutiny, especially of the kind the abolitionist would insist on. It may be that it is wrong to do the kind of research using nonhuman animals that scores of research facilities authorized by Congress around the nation do. But it is not clear why Congress is required to pass regulations which require each institution engaging in research that it (or its agents) judges to be ethically appropriate to debate the rightness or wrongness of such research. And it is far from clear that it makes sense to include an abolitionist as part of any IACUC. The IACUC is not there to shut down the place, if it can, but to enforce regulations which Congress (or its representatives) judges to be 
appropriate within the context of its broad approval of such research. The most appropriate place for the abolitionist is in the forums for public debate (including Congress, should one be able to get elected) about what policies there should be.

3. The discussion to this point has not been terribly philosophical. I now want to indicate why I am a 'moderate', thereby throwing down the gauntlet for philosophical debate.

If I knew that my son would contract multiple sclerosis (MS) when he reaches 14 , would slowly become crippled and unable to live the active life most adults take for granted, and that he would die at age 30 in what would otherwise have been the prime of his life, I would favor research that involves using nonhuman animals, specifically primates, that would certainly spare him this fate. I would favor it knowing that it involves, among other things, caging the experimental animals, performing surgery on them, subjecting them to some factor believed to cause MS, and eventually painlessly killing them. I would favor it even if it had merely a good chance of sparing him this fate.

Now to this the standard comeback is: "You wouldn't favor any of this if it involved human beings. So how can you favor it simply because it involves monkeys? What is the morally relevant difference?"

My first response to this is one of incredulity. Is one saying that if one could save one's dearly beloved young wife or daughter from some tragic disease by capturing a monkey and using it in the ways indicated in research, one would not do it? I have heard animal advocates say that they would do it, but that that wouldn't make it right. But then they're simply failing to live up to their ethical standards, and the question is why they should fail thus. Why not live up to them if they actually believe them? My guess is that they don't actually believe them. They value their loved ones a lot more than they value nonhuman animals.

My second response to this standard comeback is to say that in a state of nature, I would favor doing to human beings what I now favor doing only to nonhuman animals. I don't favor doing to humans what I propose to do to animals not because I think humans as a species possess some distinctive, inherently valuable properties but, in part, because I' $m$ in a state of society with respect to humans. In this state I've undertaken to treat them in certain ways, and to refrain from treating them in certain ways, provided they undertake to do likewise. (Consider some of these ways. I am to refrain from eating human flesh, not merely from revulsion or irrational taboo, but out of respect for human beings. I am to favor appropriate disposition of human remains, not out of health or aesthetic considerations, but out of respect. I am to prefer to kill any kind of animal rather than kill any human being, again out of respect and human solidarity implicit in the social contract. I am to think of human needs first rather than animal needs. Anyone failing to live up to these and other ways of dealing with their fellow human beings are rightly regarded as outside society to a degree, because insufficiently mindful of their fellow citizens and social mates.)

My third response is that I value lots of humans more than I value any animal. This is, obviously, not to say I don't value animals. It's not to say that I don't value them a great deal and think that a great deal that is done to them is of little value and is wrong. But why am I wrong to value lots of humans a good deal more than I value any animal? I could tell you why I do-I can talk to them, engage in various enjoyable activities with them, share their joys and sorrows, etc. You will then ask me why these are valuable, more valuable than what I can do with animals or what animals can do with each other. But then I can ask you why they are not more valuable and the question will probably end in stalemate, values and evaluation of values being what they are. I can then add, what I've already said, that I do value lots of humans a lot more than I value any animal.

The upshot is this. I'm a 'moderate' because I value my son's life, and many other human lives, more than I value any animal's life; and I live in a state of society where it is incumbent on me, and all others, to treat each other in certain ways. This state of society is something I value, something that seems essential, given my values, and something that grows out of my values, also. And, as of now, I can't see any good reason for changing it in the way abolitionists would have us do.

\section{Notes}

${ }^{1}$ Lawrence Finsen, "Institutional Animal Care and Use Committees: A New Set of Clothes for the Emperor?" The Journal of Medicine and Philosophy 13 (1988): 145-158. 